\title{
Metáfora, repetición y musicalidad. María Zambrano y Chantal Maillard
}

\author{
Lola NIETO \\ Universitat de Barcelona \\ eleuceria@hotmail.com
}

\begin{abstract}
RESUMEN
Este artículo pretende abordar dos escrituras que surgen de un mismo impulso: tratar de conocer qué es el sujeto. María Zambrano con su razón poética y Chantal Maillard con su razón estética buscan mediante la filosofía llegar a ese fondo cognitivo en el que tan intensamente se entrevera pensamiento y experiencia. Una y otra inician desde un mismo punto de arranque su andadura, comparten estrategias de viaje (la metáfora, la repetición y la musicalidad) pero el resultado es radicalmente otro. Zambrano erige un sistema metafísico donde la palabra poética es capaz de desvelar una verdad esencial y oculta, la del Ser. Maillard desactiva los conceptos heredados para señalar el mecanismo lógico del lenguaje y sus limitaciones epistemológicas. La escritura de María Zambrano anida en el pensamiento moderno. La de Chantal Maillard revienta con fiereza estos postulados para acariciar una perspectiva posmoderna.
\end{abstract}

Palabras clave: María Zambrano, Chantal Maillard, Pensamiento metafísico, Pensamiento posmoderno.

\begin{abstract}
This article deals with two writings that arise from the same impulse: the attempt of knowing what the subject is. Both María Zambrano, with the poetic reason, and Chantal Maillard, with the aesthetic reason, are trying to find, through philosophy, that cognitive background where thought and experience is so intensely intertwined. They start their walking in the same point, they share the same strategies (metaphor, repetition and music) but the result is radically different. Zambrano builds a metaphysical system in which the poetic word is able to reveal a hidden essential truth of Being. Maillard disables the inherited concepts to mark the logical mechanism of language and its epistemological limitations. The writing of María Zambrano nests in modern thought. The writing of Chantal Maillard fiercely bursts these postulates to stroke a postmodern thought.
\end{abstract}

Keywords: María Zambrano, Chantal Maillard, Metaphysical thought, Postmodern thought.

Sumario: 1. Introducción, 2. Claros del bosque y la razón poética, 3. Hilos y la razón estética, 4. Conclusiones. 


\section{Introducción}

En la década de 1930 María Zambrano inició su labor literaria y con ella llegaron las primeras tentativas de su propuesta renovadora del pensamiento: la razón poética. En 1998 Chantal Maillard publicó un ensayo titulado La razón estética, una respuesta y reformulación del método zambraniano. ¿Qué diferencia hay entre una y otra razón? ¿Qué elementos distancian y cuáles unen la razón poética de la razón estética? Ambas autoras construyen el corpus de sus respectivas obras como emanaciones de estos paradigmas epistemológicos, de modo que desentrañar los entresijos hermenéuticos de estos sistemas permite mostrar las alianzas y discrepancias que atraviesan la escritura de María Zambrano y de Chantal Maillard. Para aproximarme desde una perspectiva comparatista a estas dos razones parto de la siguiente hipótesis. Creo que ambas giran en torno a tres elementos que las explican y articulan: metáfora, repetición y musicalidad. Estos tres aspectos cobran, sin embargo, matices y sentidos distintos que progresivamente bifurcan los senderos por los que transitan la razón poética y la razón estética. Parten de un punto inicial de contacto pero finalmente son vías divergentes que abren — tal como sostiene Virginia Trueba en un artículo sobre ambas autoras - las distancias «que median entre un pensamiento moderno y un pensamiento posmoderno» ${ }^{1}$.

Para estudiar las brechas y suturas entre el lenguaje de Zambrano y el de Maillard tomaré como punto de partida - para luego saltar a otras obras - dos libros significativos en sus respectivas trayectorias: Claros del bosque e Hilos. El primero es un ensayo que María Zambrano publicó en 1977. El segundo, un poemario que Chantal Maillard dio a conocer en 2007. En ambos, filosofía y poesía se entreveran. En ambos, la escritura de sus autoras llega a un punto decisivo. En ambos, la metáfora, la repetición y la musicalidad son la urdimbre de la palabra.

\section{Claros del bosque y la razón poética}

La razón poética se abre paso en la escritura zambraniana en dos sentidos complementarios: como teoría y como praxis. Se origina como una hermeneusis que crece al tiempo que la obra toma consistencia convirtiéndose, además, en el proceso compositivo de la propia escritura. Zambrano desarrolla las cuestiones teóricas de la razón poética aplicándolas. Hace lo que dice. La razón poética está, ella misma, abordada desde la particular lógica que enuncia. Y es por eso que Zambrano no dedica un libro concreto para definirla, puesto que no es ya un concepto filosófico que deba ser explicado, clasificado y categorizado sino una actitud, un método de búsqueda, una particular mirada en la que yacen «pasión y razón unidas»². Así pues,

\footnotetext{
${ }^{1}$ V. Trueba (2009), p. 385.

${ }^{2}$ M. Zambrano (2002), p. 22.
} 
la razón poética es el nombre que recibe un camino, el camino vital e intelectual, ambos cauces imbricados, que construyó y siguió María Zambrano.

En Claros del bosque, bajo el significativo epígrafe «Método», la pensadora escribe:

Hay que dormirse arriba en la luz.

Hay que despertar abajo en la oscuridad intraterrestre, intracorporal de los diversos cuerpos que el hombre terrestre habita: el de la tierra, el del universo, el suyo propio.

Allá en "los profundos", en los ínferos el corazón vela, se desvela, se reenciende en sí mismo.

Arriba en la luz, el corazón se abandona, se entrega. Se recoge. Se duerme al fin ya sin pena. En la luz que acoge donde no se padece violencia alguna, pues que se ha llegado allí, a esa luz, sin forzar ninguna puerta y aun sin abrirla, sin haber atravesado dinteles de luz y de sombra, sin esfuerzo y sin protección ${ }^{3}$.

Zambrano, en este texto, explica el método de la razón poética. ¿Explica? Tantea. A trazos. Pinceladas. El lenguaje racionalista no es suficiente. La metáfora y la reiteración surgen entonces como intentos aproximativos. La pensadora se acerca y cerca el significado. Cada palabra es un paso, la huella de un sondeo poético. Y es que María Zambrano, partiendo del racionalismo vitalista de Ortega y Gasset y recuperando el pensamiento pitagórico y gnóstico, así como la mística, la cábala y hasta el sufismo, entiende que la filosofía de Occidente ha arraigado en una falsa dicotomía. Considerar compartimentos impermeables pensamiento y vida, conocimiento y experiencia, es para ella una fractura impuesta y reduccionista. Estas dos vertientes, el conocimiento analítico y la vivencia plena, son para María Zambrano dos modos trenzados que tenemos de aprender e interpretar la realidad. La tarea que se propone entonces consiste en encontrar una voz reconciliadora que devuelva la unidad primordial a la mirada escindida ${ }^{4}$.

En esta búsqueda, este viaje iniciático que Zambrano exige al sujeto, el individuo desciende a los inferos para despertar, es decir, para tomar consciencia de la verdad velada, la verdad esencial, el vínculo primero con el Ser, un vínculo incapaz de ser explicado por la discursividad filosófica. Esta aventura infernal, propia de algunos personajes de la mitología griega como Orfeo o Perséfone, propia también de místicos como san Juan o santa Teresa, tiene como única guía la palabra. En otro de sus libros significativos, De la aurora, Zambrano sostiene que «la palabra [...]

\footnotetext{
${ }^{3}$ M. Zambrano (2011), p. 149.

${ }^{4}$ Remito al lector a los excelentes estudios que sobre este aspecto central de la razón poética han realizado investigadores de la obra zambraniana como J. Moreno (2003), pp. 21-28; C. Revilla (2005), pp. 83-102; A. Bungård (2005), pp. 57-61; J. Larrosa (1998), pp. 131-138; o J. F. Ortega (1994), pp. 75-77.
} 
es $[\ldots]$ revelación» ${ }^{5}$. ¿Pero cualquier palabra es reveladora? Como en un conjuro, no todo sirve. Habrá que encontrar una palabra apta para tocar el misterio, capaz de atravesar el centro y decirlo, adecuada para posarse sobre el secreto y hablar desde ahí. Zambrano considera que esa palabra, no sometida al logos del lenguaje, es la palabra poética. Como explica Enrique Baena a propósito de la escritura zambraniana, «la poesía ha recogido la función, antes reservada a la filosofía, de redimir la queja de lo que clama escondido o sofocado, de lo que gime condenado y no conocemos, es decir, la unidad con que sueña el filósofo solamente se da en la poesía» ${ }^{6}$. De acuerdo con esto, podemos entender que la pensadora concibe la poesía como un vínculo con lo sagrado, una cuerda que une dos mundos: lo que percibimos y su esencia oculta. Incorporando la palabra poética a la filosofía, Zambrano convierte ésta última en un puente, un modo de escritura que como una membrana ensambla el saber racional y el saber intuitivo. La autora desestabiliza el género filosófico, como antes habían hecho Nietzsche o Heidegger y, así, siguiendo la estela de la modernidad, busca y explora una escritura híbrida capaz de dar cuenta de la doble epistemología, intelectual y experiencial, que nos vertebra.

Si regresamos al texto antes citado de Claros del bosque, podemos detectar fácilmente los elementos poéticos del lenguaje zambraniano. En primer lugar, su estructura se levanta sobre dos metáforas: la luz y la oscuridad, los dos espacios por los que transita el corazón en busca del ser primero que lo constituye. Esas dos metáforas, a la vez opuestas y complementarias, están acompañadas por estructuras repetidas que vienen a ilustrar con la prosodia la unidad escindida. Me refiero a las siguientes formaciones paralelas: «hay que dormirse arriba en la luz», «hay que despertar abajo en la oscuridad»; «el de la tierra», «el del universo», «el suyo propio»; «sin forzar», «sin abrirla», «sin haber atravesado»; «sin esfuerzo», «sin protección»; «en los profundos», «en los ínferos». Además, surgen términos derivados: «intraterrestre», «terrestre», «tierra»; «intracorporal», «cuerpos»; «vela», «desvela»; «recoge», «acoge». Y también piezas sintácticas yuxtapuestas que cumplen la misma función gramatical e insisten en un mismo sentido semántico: «intraterrestre», «intracorporal»; «vela», «se desvela», «se reenciende»; «se abandona», «se entrega», «se recoge», «se duerme».

No hay duda. La escritura de María Zambrano despliega una serie de figuras retóricas propias del lenguaje poético que inciden en la recurrencia y la reiteración. $\mathrm{Si}$ analizáramos otros fragmentos zambranianos toparíamos de nuevo con paralelismos sintácticos, derivaciones, eufemismos, anadiplosis, anáforas, polisíndeton $\mathrm{o}$, incluso, con la presencia de enunciados de un número muy parecido de sílabas, sugirien-

\footnotetext{
${ }^{5}$ M. Zambrano (1986), p. 123.

${ }^{6}$ E. Baena (2004), p. 14.
} 
do así la musicalidad de la versificación. El texto citado, como otros de Claros del bosque, podría ser un poema de Clara Janés o José Ángel Valente?

Es obvio, pues, que Zambrano defiende e introduce la poesía en su escritura para conseguir un propósito preciso: alcanzar el saber último, un conocimiento escapista del lenguaje racional. Por todo esto, ya años antes de la redacción de Claros del bosque, en Filosofía y poesía, acusa directamente a Platón del carácter discursivo y científico, por ello, mermado y precario del pensamiento occidental. Dice: «Es en Platón donde encontramos entablada la lucha con todo su vigor, entre las dos formas de la palabra, resuelta triunfalmente para el logos del pensamiento filosófico, decidiéndose lo que pudiéramos llamar "la condenación de la poesía" ${ }^{8}$. Con todo, parece que Zambrano cometió un descuido en su acusación. Aunque otros estudiosos de la obra zambraniana se han ocupado de este aspecto, creo que es significativo traer aquí el análisis que hace Chantal Maillard, puesto que nos ayudará a entender la lectura que la autora realiza de la obra zambraniana y la consecuente respuesta que supone la razón estética:

Si revisáramos los textos platónicos para ver qué tipo de poesía es en realidad aquella a la que Platón dicta sentencia, nos encontraríamos con que no es precisamente la del poeta inspirado (al que Zambrano toma por modelo), la del entusiasmado o poseído por el dios (en-theós). A este tipo de poesía, Platón la consideraba (Phedro) una locura (manía) divina similar a la oracular (mantiké) o la del enamorado. A la que dicta sentencia es a la poesía imitativa y, concretamente, a aquella poesía épica cuyo máximo representante era Homero. En realidad, a quien Platón quiere desterrar es al propio Homero que en nada se parecía a un místico?

Así pues, según Chantal Maillard, Zambrano quiere devolver al pensamiento la poesía que Platón le arrebató pero la modalidad poética que la pensadora se propone recuperar nunca fue expulsada. Y es que la poesía inspirada se asienta sobre ideas y conceptos, como lo hace el pensamiento platónico. Si tenemos en cuenta el significado que Zambrano concede a las dos metáforas que articulan el texto citado de Claros del bosque, la «luz» y la «oscuridad», descubriremos que ambas apuntan a un contenido transcendental y a una esencia primigenia que subyace oculta. Los conceptos de Verdad, Belleza y Bondad, la tríada platónica, son la búsqueda que finalmente persigue la razón poética: alcanzar ya no a decir sino a sugerir (y de ahí el ingrediente poético) el Ser, lo que todos somos bajo lo que aparentamos, el Ser imitado en la copia. Zambrano no pone en cuestión la existencia de un núcleo esen-

\footnotetext{
${ }^{7}$ De hecho, y así lo explica Carmen Revilla, se sabe que esta obra fue «redactada fragmentariamente en el exilio — concretamente en La Pièce-, con la ayuda del poeta J. A. Valente», C. Revilla (2005), p. 87.

${ }^{8}$ M. Zambrano (2000), pp. 13-14.

${ }^{9}$ Ch. Maillard (2005), p. 95.
} 
cial. Precisamente utiliza la palabra como una pértiga para llegar a ese centro o reducto sagrado. Pese a acusar diferencias, el pensamiento platónico y la razón poética son sistemas metafísicos. Así pues, se podría entender que la propuesta de Zambrano es el resultado de una combinación que aúna el concepto platónico y la fenomenología en boga desde principios del siglo XX. La mezcla de ambos ingredientes —esencia (única e inmutable) y existencia (transitoria y accidental) — da como resultado el pensamiento zambraniano.

Si la escritura de Zambrano surge a partir de una poética de la metafísica cabría, pues, cuestionarse sobre dicho lenguaje. ¿Es metafórico el lenguaje metafísico? ¿Realmente utiliza metáforas María Zambrano cuando escribe? Así lo sostuve al inicio de estas páginas, pero parece que la reflexión en torno a la razón poética está agrietando esta aseveración. En varios pasajes de su escritura, Zambrano defiende la metáfora como un instrumento que propicia la mediación entre la realidad y su esencia. En uno de ellos, «La metáfora del corazón», considera esta figura retórica como:

La función de definir una realidad inabarcable por la razón, pero propicia a ser captada de otro modo. Y es también la supervivencia de algo anterior al pensamiento, huella en un tiempo sagrado, y por tanto, una forma de continuidad con tiempos y mentalidades ya idas, cosa tan necesaria en una cultura racionalista ${ }^{10}$.

La metáfora cuyo «dominio es el ritmo» ${ }^{11}$ es, por todas estas cualidades que Zambrano le atribuye, el elemento retórico alrededor del cual orbita el lenguaje de la razón poética. Sin embargo, la propia pensadora utiliza en ocasiones como términos intercambiables metáfora y símbolo. De nuevo en «La metáfora del corazón», poco después de la cita antes mencionada, Zambrano afirma que «el corazón es el símbolo y representación máxima de todas las entrañas de la vida» ${ }^{12}$. El criterio de María Zambrano no parece fiable para determinar cuál es el mecanismo retórico de la razón poética. ¿Metáfora o símbolo? Quizá para responder a esto deberíamos antes cuestionarnos: ¿qué es la metáfora y qué es el símbolo?

Tal discusión ha llenado libros sin alcanzar un consenso unitario. Consciente de la variedad de opiniones que estas dos figuras retóricas han suscitado, considero, apoyándome en la distinción que hace Wilbur Marshall Urban ${ }^{13}$, que la diferencia

\footnotetext{
${ }^{10}$ M. Zambrano (2002), p. 60.

${ }^{11}$ M. Zambrano (2002), p. 69.

${ }^{12}$ M. Zambrano (2002), p. 69.

${ }^{13}$ Remito al lector a Lenguaje y realidad: la filosofía y los principios del simbolismo, donde Urban afirma que «la metáfora pasa a ser símbolo cuando por medio de ella encarnamos un contenido ideal y no puede expresarse de otra manera. [...] Decir que un hombre es como un zorro es un símil, decir que es un zorro es una metáfora. El es expresa una cierta identidad
} 
entre metáfora y símbolo es que en la primera la analogía activa los campos de la imaginación y la sensibilidad mientras que el símbolo requiere una intelectualización de la analogía. Una metáfora es la relación que se establece entre dos cosas debido a una semejanza de forma, color, sabor, olor... Un símbolo es la relación que se establece entre dos cosas, estando una presente y la otra ausente. La metáfora señala una conexión precisa e individualizada. El símbolo parte de un objeto determinado para apuntar a algo que está más allá. La metáfora es concreta. El símbolo, universal y conceptual.

Parece el momento de responder a la pregunta que dejé formulada: ¿el lenguaje de Zambrano es metafórico o simbólico? Considero la razón poética de Zambrano un sistema metafísico y, por ello, simbólico. María Zambrano entiende que la realidad debe ser desvelada para alcanzar su verdad y esencia. La verdad es, por tanto, algo preexistente y estable, y la palabra sugiere esa esencia previa. Como un símbolo, la dice sin nombrarla. El lenguaje de María Zambrano se construye con conceptos simbólicos, pero con conceptos. La «luz» y la «oscuridad» que articulan el fragmento de Claros del bosque así como otras figuras recurrentes en su prosa como la «sierpe», los «ínferos» o incluso el «claro» son, todos ellos, símbolos, elementos que apuntan a un significado más allá de la percepción, ubicado en un universo conceptual ${ }^{14}$.

¿Y qué sucede con la repetición y la musicalidad, derivadas de una prosa casi versificada, que antes fueron interpretadas como características complementarias de la metáfora? Ambos rasgos adquieren una función determinante desde la perspectiva simbólica. La palabra, en cuanto símbolo, vehicula algo que está fuera del lenguaje, es una representación o un reflejo de aquello que quiere expresar. En este contexto hermenéutico, la música de las palabras funciona también como una estrategia para sugerir lo que no se puede decir. La repetición en la escritura de Zambrano crea una cadencia que busca otro modo de comprensión: entender las palabras no sólo por su semántica sino por su sonoridad. La resonancia y el juego de espejos auditivos trenzan redes donde las palabras son ecos unas de otras, como los símbolos lo son de aquello a lo que apuntan. El ritmo que de estas repeticiones surge es

de intuición e idea, y el desarrollo de esto constituye el símbolo. [...] Siempre está implicada en el símbolo una identidad de intuición e idea», W. M. Urban (1952), p. 389.

${ }^{14}$ María Luisa Maillard, en un estudio sobre la escritura zambraniana, dice a este respecto: «[...] la labor de la memoria - fundamentalmente de aquella que tramita los sueños- es restituir, hacernos presente algo que "ya estaba ahí" antes de nuestra precepción, algo que es real en cuanto no ha surgido de nosotros mismos; aunque su aparición requiere de nuestra participación activa. Este sería el "mundo de los misterios" que se abriría paso a través de la imagen simbólica [...]. Diferente como vemos esta labor a la de la metáfora, que la sentiríamos nacer de la imaginación o del recuerdo consciente y que buscaría la creación de nuevos significados», M. L. Maillard (1997), p. 59. 
armónico y simétrico, símbolo acústico de la unidad original que María Zambrano pretende desvelar con la razón poética.

\section{Hilos y la razón estética}

En la primera etapa literaria de Chantal Maillard la influencia de María Zambrano es sin duda la más importante. Maillard dedica dos ensayos a la razón poética, uno de ellos fruto de su tesis doctoral. Su acercamiento a la pensadora se debe a una búsqueda intelectual y vital que nace de la sensación de que la escritura filosófica no da cuenta de la experiencia, es decir, del yo que escribe. Maillard encuentra en Zambrano el exponente de un pensamiento integrador que recibe como una solución a sus inquietudes. No sólo lee y estudia a Zambrano, entabla diálogo con ella, convirtiéndose en una voz asimilada y entreverada a la suya propia ${ }^{15}$. Como Zambrano, Maillard busca un lenguaje entre la filosofía y la poesía. Asimismo, desvía su escritura del cauce ensayístico hacia el diario, duplicando el gesto que la pensadora realizó con la confesión.

Con todo, durante la década de 1990, Maillard inicia un proceso de distanciamiento del magisterio zambraniano. Este alejamiento se debe a dos circunstancias. En primer lugar, la autora se interesa por el pensamiento posmoderno y los filósofos y escritores que lo abordan: Deleuze, Derrida, Nelson Goodman, Cornelius Castoriadis, Danto, Beckett o Michaux, entre otros. En segundo lugar, viaja a India donde pasa temporadas y se especializa en estética y religiones hindúes en la Universidad de Benarés. A los nombres citados hay que añadir, pues, estos otros: Nāgārjuna, Abhinavagupta, Bharata, Rājaśekhara y, más tarde, cuando su interés por el pensamiento oriental se extiende a China y Japón, Lao Tsé y los haikus de Santôka. Estos préstamos, los de la posmodernidad occidental y los de la tradición oriental, se amalgaman en simbiosis. Maillard busca lo mismo en unos y otros: ampliar, más bien, retorcer llevándolos al límite los temas que hasta el momento le habían preocupado. Sus reflexiones no giran ya en torno a cómo conseguir que el sujeto hable en el pensamiento sino en dilucidar qué es eso que llamamos sujeto. Surge entonces la diferencia fundamental entre María Zambrano y Chantal Maillard. Maillard desconfía del lenguaje, Zambrano cree en él. Maillard inicia una tarea deconstructiva que atraviesa, a partir de este momento, toda su obra y que consiste en cuestionar el sentido heredado de las palabras. Zambrano nunca pone en tela de juicio los con-

\footnotetext{
${ }^{15}$ Virginia Trueba sostiene que en sus inicios literarios Maillard se identifica de tal modo con Zambrano que incluso en su libro La creación por la metáfora se duda «si Maillard está hablando de Zambrano o de ella misma. Al mismo tiempo, y esto es sumamente interesante en tanto constituye un ejemplo de cómo actúa la "razón poética", Maillard inicia aquí un diálogo con el sujeto-objeto de su estudio que le permite alimentar, como ella misma reconoce, su propia creatividad», V. Trueba (2009), p. 396.
} 
ceptos, los emplea para construir su razón poética. Maillard, por el contrario, adopta en su escritura la metáfora como mecanismo para escapar precisamente de ellos ${ }^{16}$.

Explica Maillard en La razón estética:

La razón estética [...] va más allá de la razón-poética porque no interpreta el mundo sino que construye mundos [...]. Cuando interpreta, cuando expresa, lo hace a sabiendas de que todo decir es la expresión temporal de un entramado que, apenas expresado se desteje, invalidando lo expresado. El arte de este hacer comprensivo, al que por ello llamamos razón «estética», consiste en lograr que nada coagule en conceptos ${ }^{17}$.

Este fragmento es interesante no sólo porque explica la distancia que se abre entre una y otra autora sino porque, además, dibuja el camino que se extiende desde la primera escritura de Maillard hasta Hilos. Para mostrarlo, propongo la lectura de dos poemas. El primero pertenece a Hainuwele, poemario publicado en 1990 y por tanto todavía bajo el influjo zambraniano:

En el centro de todo lo que vive hay un lugar, un hueco transparente al que llaman espíritu.

Es allí donde viertes tu poder

$\mathrm{y}$ te transformas,

es allí donde haces

a cada ser distinto de los otros.

Y por eso el espíritu es un don,

el don de ser sí mismo,

aquel que nos otorgas cuando la luz despunta

y vienes a habitar los huecos transparentes.

Sé que eso ocurre cuando oigo tu risa

bajar como una ardilla desde los altos cedros ${ }^{18}$.

En Hainuwele, una voz en primera persona transita los poemas y los articula como los pasos de un viaje hacia el ser original encarnado en el personaje del Señor

\footnotetext{
${ }^{16}$ Nuño Aguirre de Cárcer sostiene que Maillard procura y consigue superar en su escritura «la filiación platónica de las imágenes que Zambrano utiliza en su obra. Las oposiciones ontológicas esencia/apariencia, oculto/revelado, profundidad/superficie son el sustento de las metáforas con las que Zambrano da vida a su propuesta [...]. Estos símbolos, aunque son propios y originales de Zambrano, son profundamente deudores de una concepción dualista (y platónica) de la existencia. [...] Toda esta concepción de la realidad es tajantemente rechazada por Maillard [...] que toma conciencia de las imposturas ocultas en las metáforas heredadas y trata de construir un universo metafórico personal que escape de (y denuncie) estas dicotomías transmitidas por el lenguaje», N. Aguirre de Cárcer (2012), p. 91.

${ }^{17}$ Ch. Maillard (1998), p. 150.

${ }^{18}$ Ch. Maillard (2009), p. 61.
} 
de los Bosques, el tú al que se dirige la escritura. Aunque Maillard ya había viajado a India y de ahí que se pueda detectar la pista del pensamiento oriental en estos versos, Zambrano sigue imponiéndose como la presencia más evidente. En el poema citado, el léxico parece surgir de la prosa zambraniana. Se alude a un «centro», un «hueco transparente al que llaman espíritu» que es el «don», así como se hace referencia a la «luz» y a la transformación. Este último concepto, de hecho, es el que acerca más el poema a Zambrano. El ser original, uno y único, se transforma dando así lugar a los seres. Las manifestaciones fenomenológicas son, en definitiva, modulaciones de la esencia preexistente, emanaciones del centro. En cada ser habita el Ser. Entender las expresiones accidentales como incorporaciones de la verdad esencial es una huella obvia de la razón poética.

Veamos ahora el segundo poema, éste de Hilos:

Cual asomado a otro.

Articulado.

Extrañado.

Entrañado.

Extrañado.

Entrañado.

Hastiado ${ }^{19}$.

Si comparamos el poema de Hainuwele con el de Hilos, las diferencias que se aprecian son tan acentuadas que incluso podríamos afirmar que parecen de autores distintos. Y sí. Es cierto. Maillard cuando escribe Hilos está profundamente alejada de su propia escritura inicial. Escribir, para la autora, es un método de conocimiento y por eso su andadura, honesta y sincera, la ha llevado a descreer de sus primeros trabajos, a descreer incluso de sí misma, a ponerse en duda y cuestionarse en el fiero y brutal viaje hacia el rostro atónito e impuro de la extraña criatura viva que somos. Maillard, cuando escribe Hilos es otra persona, más que eso, ha desactivado los conceptos que nos hacen concebirnos a nosotros mismos como personas o sujetos.

Hilos es una topografía de la mente. El trabajo de observación de Maillard consiste en verse a sí misma transitar por sus pensamientos y estados anímicos. Desidentificada de sí, desdoblada (como se aprecia en el poema citado), Maillard concluye que los sentimientos se suceden y el yo, en ese encadenamiento de emociones, surge como un falso receptáculo o escenario. No hay un ser en el que acontezcan emociones, sino emociones como destellos y fogonazos. El lenguaje (y el pensamiento también, en cuanto se construye lingüísticamente), para dar cuenta de las experiencias sensoriales y mentales, precisa de una pieza gramatical que se identifique con el enunciado emitido. El yo es esa pieza. Gramática a la que hemos otorga-

${ }^{19}$ Ch. Maillard (2007), p. 153. 
do esencia. Así pues, en Hilos, el lenguaje es para Maillard, como para ciertos pensadores de la posmodernidad y de la tradición hindú, un sistema representacional de signos. Y en este sentido la autora, como señala Aguirre de Cárcer, «reivindica la metáfora, entendida como proceso mental y no como mero tropo [...], como el mecanismo idóneo para lograr la toma de conciencia y la autoconstrucción consciente de la persona: el despertar» ${ }^{20}$.

Ahora bien, para comprender el alcance metafórico de los poemas en Hilos es necesario acudir a las enseñanzas de Nāgārjuna. En el siglo II o III, en India, Nāgārjuna fundó la escuela madhyamaka, o de la vía media, que suponía una vuelta de tuerca del budismo mahayana, incidiendo en la vacuidad y en la inutilidad del lenguaje para dar cuenta de la realidad en sí. Nāgārjuna, anticipándose en varios siglos a la modernidad filosófica occidental, señala los dualismos con los que opera la mente y los considera limitados para una comprensión abarcadora. Descubre las imbricaciones entre pensamiento y lenguaje y entiende que el pensamiento está supeditado a la lógica lingüística, de modo que pensamos tan sólo aquello que lingüísticamente somos capaces de formular. De ahí que lo que llamamos conocimiento sea, para Nāgārjuna, lo que lingüísticamente podemos conocer. El pensador llega así a la siguiente conclusión: si el pensamiento es lingüístico y el lenguaje es lógico, el pensamiento teleológico es al fin y al cabo un artificio lógico también. A partir de ahí, la tarea de Nāgārjuna consiste en poner lógica arriba los conceptos que se hacen pasar por verdades ontológicas ${ }^{21}$, trasladando así el foco de estudio de la metafísica a la lógica y, como consecuencia, entendiendo el sentido de las palabras según su función dentro del sistema que las crea. Dicho de otro modo: para Nāgārjuna el significado se desprende del contexto, de la relación que establece un término con los otros que lo acompañan. Así, las palabras están abiertas semánticamente a las transformaciones que la disposición contextual les aporta. Si las piezas gramaticales adquieren significado por sus movimientos relacionales, entonces, no se pueden considerar conceptos cerrados, con un sentido predeterminado e inamovible, sino conceptos abiertos o metáforas. Un lenguaje metafórico no recurre a la metáfora como figura retórica ornamental; por el contrario, la considera la operación herme-

\footnotetext{
${ }^{20}$ N. Aguirre de Cárcer (2012), p. 95.

${ }^{21}$ Uno de esos conceptos de los que Nāgārjuna se ocupa es el sujeto. Dice: «Algunos sostienen que el sujeto que experimenta las impresiones de los sentidos (ver, oír, etc.) y las sensaciones internas debe de existir antes que éstas, ya que una entidad que todavía no existe no podría tener experiencias visuales o de otro tipo. Pero ¿de qué forma se podría dar a conocer una entidad anterior al ver, al oír, al sentir, etc.? ». Y más adelante: «Ni la existencia, ni la no existencia, de un yo sustancial puede probarse de ninguna forma. Sin eso - sin el àtman — ¿cómo se podrá probar la existencia, o la inexistencia, de las turbaciones (kleśa)?», Nāgārjuna (2004), pp. 103 y 165. Nāgārjuna no deja percepción con cabeza, ni percepción ya siquiera. Se reduce el pensamiento a pura lógica gramatical. Hace falta el requiebro posmoderno del segundo Wittgenstein para igualar algo así.
} 
néutica que levanta el aparato gramatical y sintáctico. El lenguaje (como sistema) funciona al modo en que lo hace la metáfora (como tropo). De esta manera, se podría decir que la lógica madhyamaka de Nāgārjuna se anticipa a las teorías sobre el lenguaje que la filosofía y la crítica literaria posmodernas han desarrollado bajo los trabajos de Genette, Barthes, Derrida o Paul de Man.

El lenguaje de Hilos crece mediante modulaciones metafóricas. En el poemario de Maillard juega un papel importante el pensamiento contemporáneo pero es fundamental, en su caso, el sustrato oriental en el que la escritora encuentra el origen de las derivaciones filosóficas actuales. Así pues, en mi opinión, las enseñanzas de Nāgārjuna están en la base de la metáfora lingüistica de la escritura de Hilos. ¿Y por qué lo considero un lenguaje metafórico? En Hilos, mediante el mecanismo de la repetición, se despliegan redes de referencias entre los poemas, provocando incesantes matices semánticos que, convocándose, impiden que el significado concluya y se cierre. Así pues, los mecanismos de repetición son los que hacen evidente el uso de un lenguaje metafórico.

En el segundo poema del libro, titulado «Hilos»—creando así una repetición del título del poemario-, leemos:

Permanecer - ¿permanecer? - la carne herida. Hay cicatriz.

$\mathrm{Y}$ en la parte final de este mismo poema, Maillard escribe:

Quedar en lo reconocible.

— ¿Quedar? - Permanecer. Ya dije

permanecer. Ya pregunté.

En un poema se hace referencia explícita a ese mismo poema, incurriendo en una autocita que pone en evidencia la trama reflexiva de la escritura y la representación del acto escriturario. Este juego también se produce entre distintos poemas. En el que da inicio al poemario, titulado «Uno», se lee:

Partir es dar pasos fuera.

Fuera de la habitación.

De la mente, no:

no hay. Hay hilo.

Y en el siguiente, «Hilos», ya citado antes, encontramos:

Partir es dar pasos fuera.

Fuera de la habitación.

De la mente, no. - ¿Mente?-

Ya pregunté. Y no hay. Hay hilo. 
Pero aquí no se detienen las multiplicaciones de esta escritura caleidoscópica. En otra sección de la primera parte del poemario, aparecen estos versos:

Avanzar es dar pasos fuera.

Aunque eso ya lo dije en alguna

parte, ¿o era partir?, partir es

dar pasos fuera. Es igual.

Así pues, aparecen enlazados, en primer lugar, dos poemas de una misma sección (titulada «Poemas-Husos») y, más tarde, éstos se vinculan, mediante la repetición, con otro poema de una sección distinta (titulada «La calma»). Este desdoblamiento de versos, que se reitera a lo largo de todo el poemario, no es sólo una manera de conectar diversos momentos del libro, es sobre todo la estrategia retórica para señalar la condicionalidad de la escritura que, resonando entre sí, teje una lógica textual próxima a la de la red. De hecho, todavía queda por señalar otro nivel de conexión. Todos los poemas de la primera sección de Hilos, los incluidos bajo el título «Poemas-Husos», son reelaboraciones poéticas de fragmentos en prosa de otro libro anterior de la autora, el diario Husos. Maillard toma su propia escritura en prosa y la reescribe en forma de poema. En Husos ya había escrito: «Quedar en lo reconocible. Quedar - iquedar? —: permanecer. Ya dije permanecer. Ya pregunté» ${ }^{22}$. La expresión «ya pregunté», idéntica en una y otra situación textual (el diario y el poemario), no significa lo mismo en cada una de ellas, o más bien, señala situaciones lingüísticas diferentes. En el caso del fragmento en prosa, «ya pregunté» hace alusión al inicio de ese mismo cuadro narrativo de Husos, en concreto, a estas palabras: «Permanece — ¿permanecer? - la carne herida. Hay cicatriz $\rangle^{23}$. Cuando algunos párrafos más tarde, la voz de la escritura dice: «permanecer. Ya dije permanecer. Ya pregunté» ${ }^{24}$, es evidente que se refiere a la pregunta que abría el texto. Ahora bien, en el caso poético, no está tan claro a qué hace referencia: ¿a la pregunta que se inscribe al inicio del poema o a esta misma pregunta que aparecía antes en la prosa del cuaderno?

En Husos, la expresión «ya pregunté» señala el principio del fragmento; en Hilos, el principio del poema y el del fragmento de Husos, simultáneamente. De este modo, una construcción lingüística exacta varía de sentido al variar de contexto: dice (fonéticamente) lo mismo, pero no dice (semánticamente) lo mismo. Las reelaboraciones entre Husos e Hilos ponen en evidencia no sólo la relacionalidad lingüística de la que hablaba Nāgārjuna sino también estas palabras de Derrida:

A causa de su iterabilidad esencial, siempre podemos tomar un sintagma escrito fuera del encadenamiento en el que está tomado o dado, sin hacerle perder toda posibilidad de funcionamiento [...]. Podemos, llegado el caso, reconocerle otros

${ }^{22}$ Ch. Maillard (2006), p. 63.

${ }^{23}$ Ch. Maillard (2006), p. 63.

${ }^{24}$ Ch. Maillard (2006), p. 64. 
inscribiéndolo o injertándolo en otras cadenas. Ningún contexto puede cerrarse sobre él ${ }^{25}$.

Si bien el contexto determina el sentido (circunstancial) de un signo lingüístico, su capacidad de repetición en otros infinitos contextos impide que jamás puedan detenerse los significados que se le podrán atribuir. Al introducir motivos lingüísticos similares en cadenas o situaciones comunicativas distintas, éstos siguen funcionando pero alteran su sentido. La expresión hueca «ya pregunté» del poema de Hilos no señala ningún referente concreto sino esta característica del lenguaje que Derrida menciona, es decir, la relación entre la iteración y la recontextualización de las expresiones lingüísticas en la construcción de su sentido, ideas puestas a flor de escritura en Hilos.

La interdependencia semántica de las palabras, que Nāgārjuna llamaba vacuidad o condicionalidad, conlleva que entre sí los términos funcionen como metáforas unos de otros, adquiriendo sentido en el cruce de sus conexiones. No hay un sentido unívoco, sino posibilidades ilimitadas producidas por la iteración también ilimitada de contextos interpretativos. Las repeticiones en Hilos convierten la palabra en metáfora, generan contextos donde decir lo mismo ya no tiene un sentido idéntico. Desestabilizan la unidad semántica y trascendental de los conceptos.

¿Y la música? La música en el lenguaje metafórico y reiterado de Hilos no es sinfónica ni armoniosa ni es símbolo de una unidad primordial, como sucedía en la escritura de Zambrano. Por el contrario, en Hilos la música del lenguaje es sincopada, fragmentada y atonal. Como en una composición dodecafónica, en el poemario de Maillard, la escritura balbucea, cuestiona también así y desde la enunciación el sentido de las palabras.

\section{Conclusiones}

El lenguaje de la razón poética y el de la razón estética, así como la escritura que de estos paradigmas se destila, convierte a María Zambrano y a Chantal Maillard en dos posibles exponentes, dentro de la literatura española contemporánea, del pensamiento moderno, la primera, y del pensamiento posmoderno, la segunda. Ambas escrituras surgen de una inquietud compartida: buscar un lenguaje capaz de decir, en el pensamiento, la vivencia. Zambrano y Maillard ansían conocer y conocerse. Pero el resultado de estos sondeos desemboca en obras prácticamente en las antípodas. Zambrano entiende que el individuo, el sujeto, puede acceder a un conocimiento metafísico de sí mismo. Maillard considera que la metafísica es lógica y que el sujeto, por tanto, es un concepto lógico también. En Zambrano hay trascendencia; en Maillard, lenguaje. Por eso la palabra en la escritura de María Zambrano es simbólica y su reiteración, una técnica para sugerir con la música la unidad oculta. La palabra en la escritura de Chantal Maillard es, por el contrario, metáfora y no apunta a un significado más allá sino que construye sus sentidos en el

\footnotetext{
${ }^{25}$ J. Derrida (1998), p. 358.
} 
juego de sus aplicaciones, transformándolos según la necesidad del contexto. No hay verdad a la que apuntar con la palabra sino verosimilitud construida con ella. La reiteración es entonces el mecanismo que modula la música del balbuceo, una música que, como el lenguaje, es consciente de su tarea: construir y deconstruir discursos.

\section{OBRAS CITADAS}

AGUIRRE DE CÁRCER, Nuño: La actitud contemplativa a través de la obra de Chantal Maillard, Tesis doctoral dirigida por Tomás Albaladejo y Ángel García, Universidad Autónoma de Madrid, 2012.

BAENA, Enrique: El ser y la ficción. Teorías críticas de la literatura, Barcelona, Anthropos, 2004.

BUNDGÅRD, Ana: «Ética y estética de la razón poética», en Pedro Cerezo (ed.), Filosofía y literatura, Sevilla, Fundación José Manuel Lara, 2005, pp. 55-76.

DERRIDA, Jacques: Márgenes de la filosofia, Madrid, Cátedra, 1998.

LARROSA, Jorge: «Sobre el camino recibido, o la delicada conjunción entre método, vida y experiencia», en Carmen Revilla (ed.), Claves de la razón poética, Madrid, Trotta, 1998, pp.131-138.

MAILLARD, Chantal: La razón estética, Barcelona, Laertes, 1998.

: Husos, Valencia, Pre-Textos, 2006.

: Hilos, Barcelona, Tusquets, 2007.

: «La violencia de la palabra. Algunas consideraciones acerca del origen de la poesía y la filosofía», en Laura Silvestri (ed.), Il pensiero di María Zambrano, Udine, Forum, 2005, pp. 85-98.

: Hainuwele y otros poemas, Barcelona, Tusquets, 2009.

MAILLARD, María Luisa: María Zambrano: la literatura como conocimiento y participación, Lleida, Edicions de la Universitat de Lleida, 1997.

MORENO, Jesús: La razón en la sombra. Antología crítica, Madrid, Siruela, 2003.

NĀGĀRJUNA: Fundamentos de la vía media, Juan Arnau (ed.), Madrid, Siruela, 2004.

ORTEGA, Juan Fernando: Introducción al pensamiento de María Zambrano, México, Fondo de Cultura Económica, 1994.

REVILLA, Carmen: «Sobre el lenguaje de la razón poética», en Entre el alba y la aurora, Barcelona, Icaria, 2005, pp. 83-102.

TRUEBA, Virginia: «De la metafísica a la lógica (sobre María Zambrano y Chantal Maillard)», Boletín de la Biblioteca Menéndez Pelayo, 85 (2009), pp. 385-406.

URBAN, Wilbur Marshall: Lenguaje y realidad: la filosofia y los principios del simbolismo, México, Fondo de Cultura Económica, 1952.

ZAMBRANO, María: De la aurora, Madrid, Turner, 1986. : Filosofía y poesía, México, Fondo de Cultura Económica, 2000. : Hacia un saber sobre el alma, Madrid, Alianza, 2002.

: Claros del bosque, Madrid, Cátedra, 2011. 